\title{
Update to the difficulties in diagnostic and therapeutic management of the rare carpometacarpal joint II-V dislocation injuries: Case presentation and review of literature
}

\author{
Ingo Schmidt* \\ Medical Centre Wutha-Farnroda GmbH (Department of Orthopaedics, Traumatology and Hand Surgery), Ringstr. 20, 99848 Wutha-Farnroda, Germany
}

\begin{abstract}
This case report describes specific features and difficulties about the rare carpometacarpal joint dislocation injury. The carpometacarpal joint IV seems to be the main problem in radiographic assessment because it is partially overlapped by the hook of the hamate bone. Therefore, computed tomography scans should be done in every instance especially after a closed reduction procedure. When joint transfixations become necessary, then the K-wires should not cross the midcarpal joint in order to obtain early wrist motion.
\end{abstract}

\begin{abstract}
Abbreviations: CMCJ: Carpometacarpal joint; MCPJ: Metacarpophalangeal joints; K-wires: Kirschner-wires; CT: Computed tomography; ORIF: Open reduction and internal fixation

\section{Introduction}

Dislocation involving one or more carpometacarpal as well as metacarpophalangeal joint(s) (CMCJ, MCPJ) with or without concomitant fractures (i.e. fracture-dislocation injury) is a rare high-energy injury with various pattern, it can be associated with a polytrauma after traffic accidents, and it is observed of both in dorsal and in volar direction [1-4]. Normally, the CMCJ space of an uninjured hand is clearly visible and limited by the parallel running articular surfaces. Typically for a dislocation, the joint space is not visible due to an overlapping of the carpal articular surface by the base of the opposing metacarpal bone in the posterior-anterior (PA) radiograph, however, this sign can not often easily assessed potentially leading to a missed diagnosis of a primary injury [5,6], or a persistent or recurrent (sub)dislocation after closed reduction such as presented with our case.
\end{abstract}

\section{Case presentation}

A 46-year-old male sustained a polytrauma (Injury Severity Score 5, scale 1-6) due to a car accident associated with multiple fractures of the ribs that led to a right pneumothorax, the left clavicle, the right distal femur, the left lower leg, the left radius shaft, the left hand, and CMCJ II-V dislocations at his right hand [Figures 1A-E, Figure 2A]. Primarily, a closed reduction with transfixation of the CMCJ II and V (i.e. border digit rays) utilizing two percutaneously drilled K-wires was done and intraoperative fluoroscopy showed well-aligned CMCJs II-V as suggested by us [Figure 2B], noted that persistent (sub)dislocations as well as joint instabilities could not observed in the lateral and oblique plane with dynamic fluoroscopy. However, the PA radiograph one day after surgery did not allow an exact assessment of the CMCJ IV [Figure $2 \mathrm{C}]$. Therefore, a computed tomography (CT) scan was detected by us that revealed persistent or recurrent subdislocation of the CMCJ III [Figure 2D], and nearly complete dislocation of the CMCJ IV [Figure 2E]. Moreover, CT scan demonstrated impressively that the CMCJ IV could not sufficiently assessed in the postoperative radiograph because this joint was ulnar-sided completely overlapped by the hook of the hamate bone [Figure 2E]. An open reduction became necessary secondarily with joint transfixations utilizing two K-wires for each joint which did not cross the midcarpal joint that allows an early active movement for the wrist too [Figures 3A-B]. The hand was immobilized with a plaster splint for two weeks, after that, movement of the wrist and all finger joints were freed without load for another four weeks. The K-wires were completely removed three months after second surgery. At the 1-year follow-up, there were unchanged stable and well-aligned CMCJs II-V but with pronounced signs of post-traumatic osteoarthritis of the CMCJ IV and V radiographically [Figure 3C], and function of all finger joints had been completely restored [Figure 3D].

\section{Discussion}

Main causes for polytraumata are traffic accidents (cars, motorcycles, bicycles, pedestrians) with a relative portion ranging from $65-88 \%$, and followed by accidental and suicidal falls $[7,8]$. Most frequently observed in polytraumatized patients are fractures of the long bones with a relative portion of $86 \%$ (most frequently fractures at the lower extremities with a male predominance), whereas injuries at the

*Correspondence to: Ingo Schmidt, Medical Centre Wutha-Farnroda GmbH (Department of Orthopaedics, Traumatology and Hand Surgery), Ringstr. 20, 99848 Wutha-Farnroda, Germany, E-mail: schmidtingo62@googlemail.com

Key words: polytrauma, carpometacarpal joint, dislocation injury, anatomical landmarks, computed tomography, reduction

Received: March 09, 2021; Accepted: March 19, 2021; Published: March 26 2021 
Schmidt I (2021) Update to the difficulties in diagnostic and therapeutic management of the rare carpometacarpal joint II-V dislocation injuries: Case presentation and review of literature

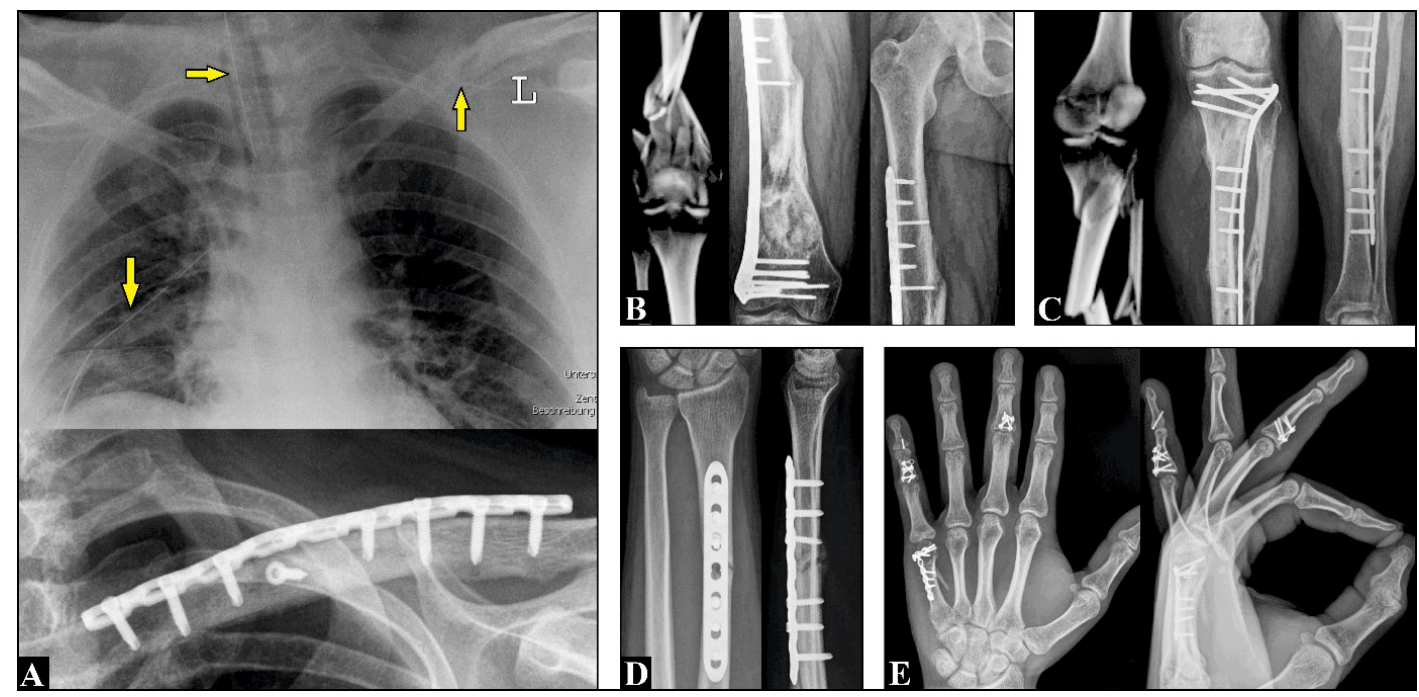

Figure 1 (Case presentation). (A) The radiograph of the chest showing the intratracheal tubulus for the the required arteficial respiration, the right intrathoracic drain for treatment of the pneumothrax, and the fracture of the left clavicle (arrows). The fracture of the clavicle was treated by ORIF. (B) The highly comminuted right distal femoral fracture was definitively treated by ORIF after initial external fixation. (C) The highly comminuted fracture of the left lower leg was definitively treated by ORIF after initial external fixation. (D) The left radius shaft fracture was treated by ORIF. (E) The multiple fractures of the left hand were treated by ORIF
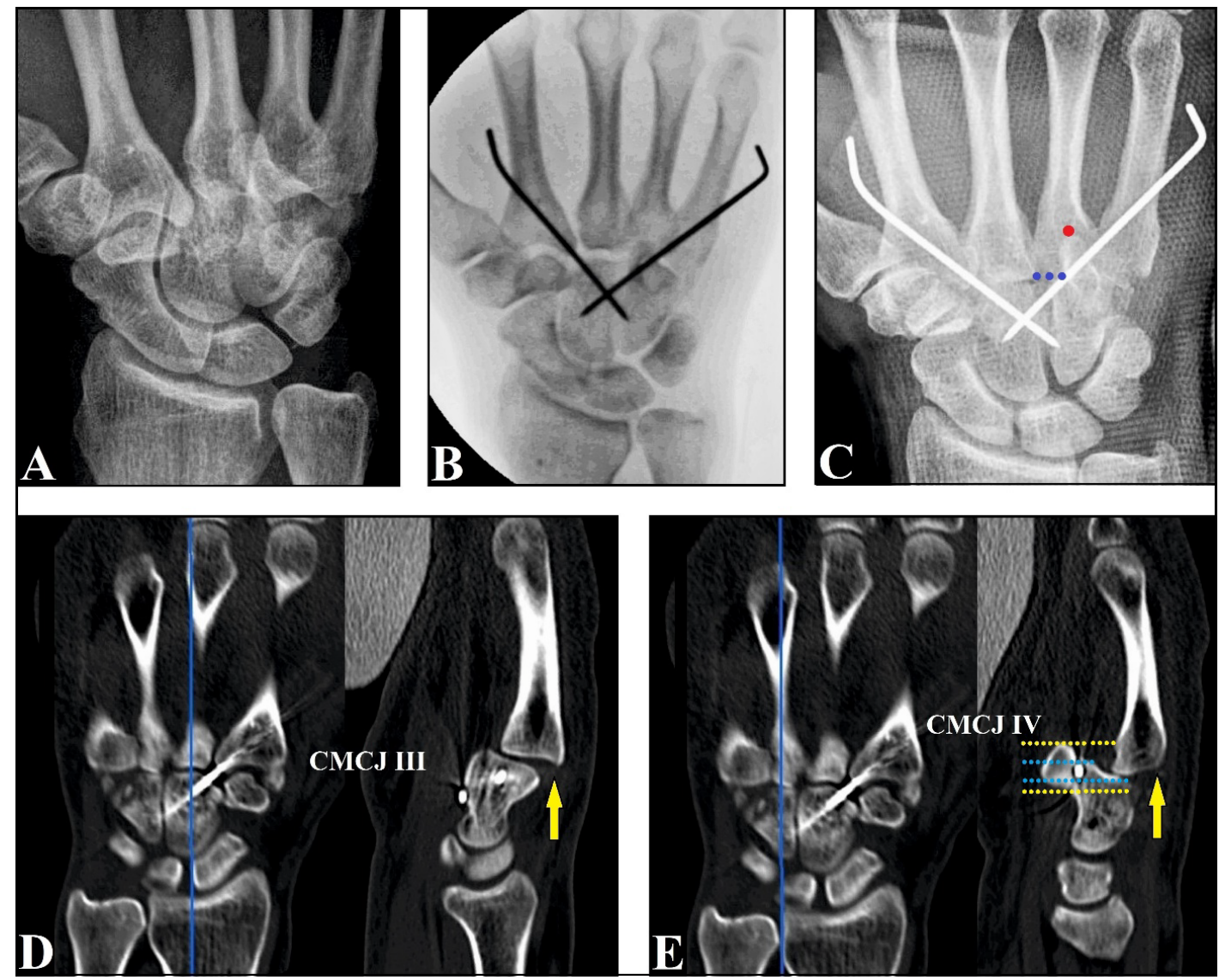

Figure 2 (Case presentation). (A) Initial PA radiograph of the right hand demonstrating the typical overlapping in the CMCJs II-V. (B) Intraoperative fluoroscopy after closed reduction showing the K-wire transfixation of the border digit rays. Note that the CMCJ II-V joint spaces are well visible suggesting correctly performed reductions. (C) Postoperative PA radiograph after closed reduction confirmed the intraoperative findings, however, the CMCJ IV could not clearly assessed. The red dot marks the distal shadow of the apex of the hook of the hamate bone which is more distally located than the joint space (blue dotted line). (D) Sagittal CT scan after closed reduction showing the persistent or recurrent subdislocation of the third metacarpal bone against the capitate bone in dorsal direction (arrow). (E) Sagittal CT scan after closed reduction showing the persistent or recurrent nearly complete dislocation of the fourth metacarpal bone against the hamate bone in dorsal direction (arrow). Note that the articular space of the hamato-metacarpal joint (light blue dotted lines) is ulnar-sided completely overlapped by the hook of the hamate bone (yellow dotted lines) 
Schmidt I (2021) Update to the difficulties in diagnostic and therapeutic management of the rare carpometacarpal joint II-V dislocation injuries: Case presentation and review of literature
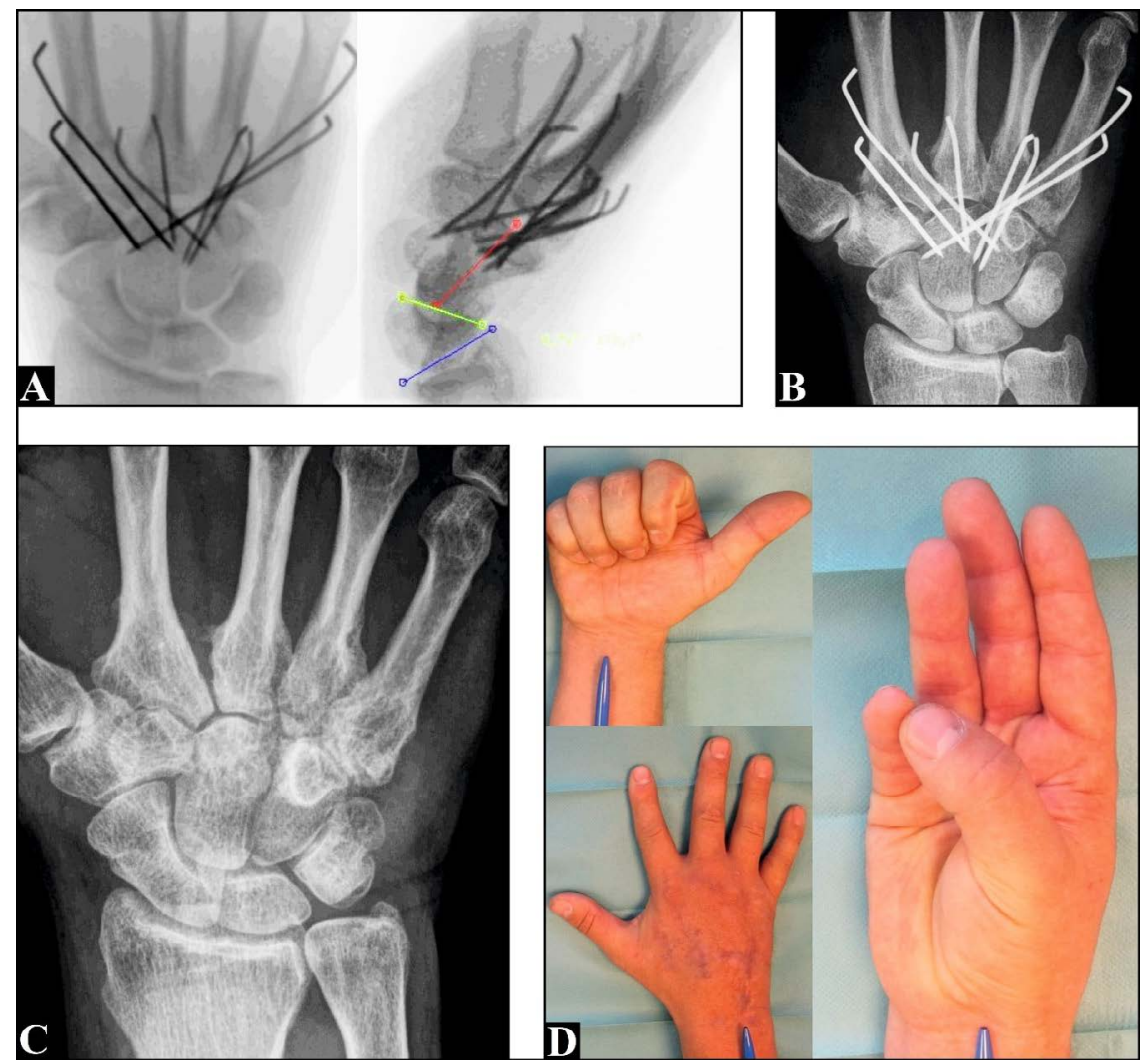

Figure 3 (Case presentation). (A) Intraoperative fluoroscopy after open reduction and K-wire transfixation without crossing the midcarpal joint showing well-aligned CMCJs II-V. The three colored lines on the lateral view demonstrating the relative portion of both the radiocarpal and the midcarpal joint at terminal range of extension in the absence of persisting CMCJ instabilities (i.e dynamic fluoroscopy). (B) PA radiograph after open reduction demonstrating well-aligned CMCJs II-V too. (C) PA radiograph at the 1-year follow-up demonstrating unchanged well-aligned CMCJs II-V, but there are pronounced signs of post-traumatic osteoarthritis at the CMCJ IV and V. All K-wires were removed three months after open reduction. (D) Clinical photographs at the 1-year follow-up showing the complete functional restoration of all finger joints

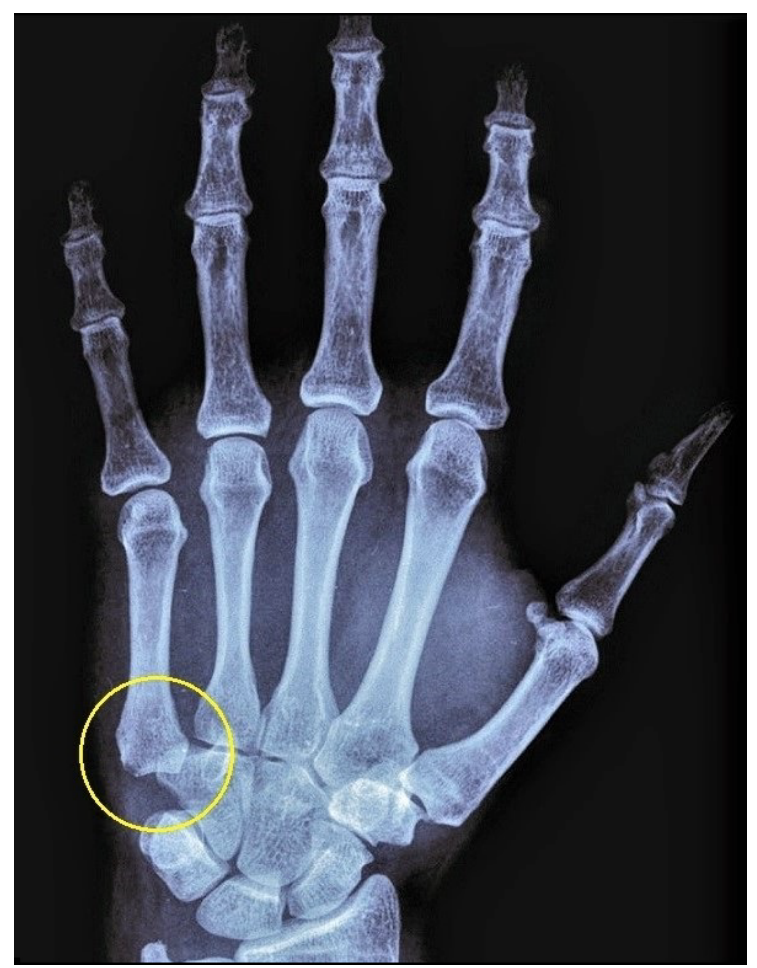

Figure 4 (57-year-old female, after a fall downstairs). PA radiograph of the left hand showing the isolated CMCJ V dislocation injury. Note the elapsed Gilula's third arc between the fifth metacarpal and the hamate bone, and the interrupted broad letter „,M“ configuration in the CMCJ V due to the dislocation of the metacarpal bone in dorsal and ulnar direction (circle) 

and review of literature

hand with a relative portion in up to $3.3 \%$ are clearly underrepresented $[1,9,10]$. The risk of getting hand injuries in polytraumatized patients is reported to be in up to $20 \%$ (excluding distal radius fractures), and in $75 \%$ of all cases carpal or metacarpal fractures were found [11]. CMCJ (fracture-)dislocation injuries represent less than $1 \%$ of all hand and wrist injuries, and it is mainly caused in $54 \%$ by punches, followed by traffic accidents in $23 \%$ and by falls from height in $14 \%$ of cases [12-14].

The CMCJs II-V are saddle joints (comparable with the CMCJ I) that are stabilized like an amphiarthrosis by the volar and more stronger dorsal ligaments, intermetacarpal and transverse ligaments, the long flexor and extensor tendons, the intrinsic muscles of the hand; and the ulnar-sided CMCJs (II, III) are more mobile than the radialsided CMCJs (IV, V) $[15,16]$. In direction to the proximal carpal row the opposing joint surfaces of the capitate and hamate bone form up to the concave to distally third Gilula's arc [17]. In distal direction, the uninjured CMCJs showing parallel running articular surfaces to the opposing metacarpal bones with a distance of $1.0-2.0 \mathrm{~mm}$ and forming a broad letter "M“ $\mathrm{M}^{\prime}$ configuration [12]. The CMCJ III is more proximally located than the other joints producing the keystone phenomenon for load transfer through the wrist [18]. CMCJ dislocation injuries can be caused by the apply of either direct or indirect forces. Direct forces can occur by the abrupt reflexive clasping of the handlebars (cars or motorcycles) during the sudden impact such as suggested by us with our case, and indirect (i.e. axial) forces especially by an intercepting reaction of the hand in the event of a fall or by punches $[11,14,19,20]$. The direction of dislocation depends on the position of the wrist at the time of the impact (in dorsal direction when the wrist is held in flexion and vice versa). Dislocations in dorsal directions are more common than in volar direction, and dislocations of the CMCJ IV and V are more common than the CMCJ II and III due to its anatomical pre-existing higher mobility [Figure 4] [16,21]. Subdislocation implies the rupture of at least the intermetacarpal ligament, and complete dislocation the rupture of both palmar and dorsal ligaments [20].

Divergent multiple CMCJ dislocations are possible as well. It is defined as volar dislocation of $\geq 1$ joint with concomitant dorsal dislocation of $\geq 1$ joint, and this variant of injury is caused of either by a twisting mechanism represented by supination of the metacarpal arc around an axis passing between the third and fourth metacarpals, or by a direct impact immediately followed by a rotatory force $[22,23]$. Noted that CMCJ dislocations can be associated with concomitant MCPJ (fracture-)dislocation injury as well $[24,25]$. Moreover, Gaheer and Ferdinand [26] reported about one case with a third metacarpal base fracture associated with primarily missed dislocations of the CMCJ IV and V, Brinkman et al. [27] observed one case with CMCJ II-V dislocations associated with a concurrent fracture of the hamate bone, and Feder et al. [28] reported about one case with a $180^{\circ}$ in situ dislocation of the trapezoid bone associated with concomitant CMCJ II and III dislocations. Noted was well that a newest study including 139,931 polytraumatized patients revealed that the relative portion of primarily missed hand injuries is $6.6 \%$ (excluding distal radius fractures), and $11.2 \%$ of these patients sustained carpal fractures/ dislocations [29].

In diagnostic management $\mathrm{PA}$, lateral and $45^{\circ}$ oblique radiographs are recommended, and intraoperative dynamic stress fluoroscopy can be helpful as well $[21,26,30]$. However, in up to $70 \%$ of cases (sub) dislocations can be overlooked [5]. Therefore, CT is recommended primarily if a (sub)dislocation injury is clinically suggested but not correctly assessed by radiographs. With our case, there were persistent or recurrent (sub)dislocations after closed reduction that could not correctly assessed by us of both in intraoperative fluoroscopy and postoperative radiographs, and the CMCJ IV seems to be the main
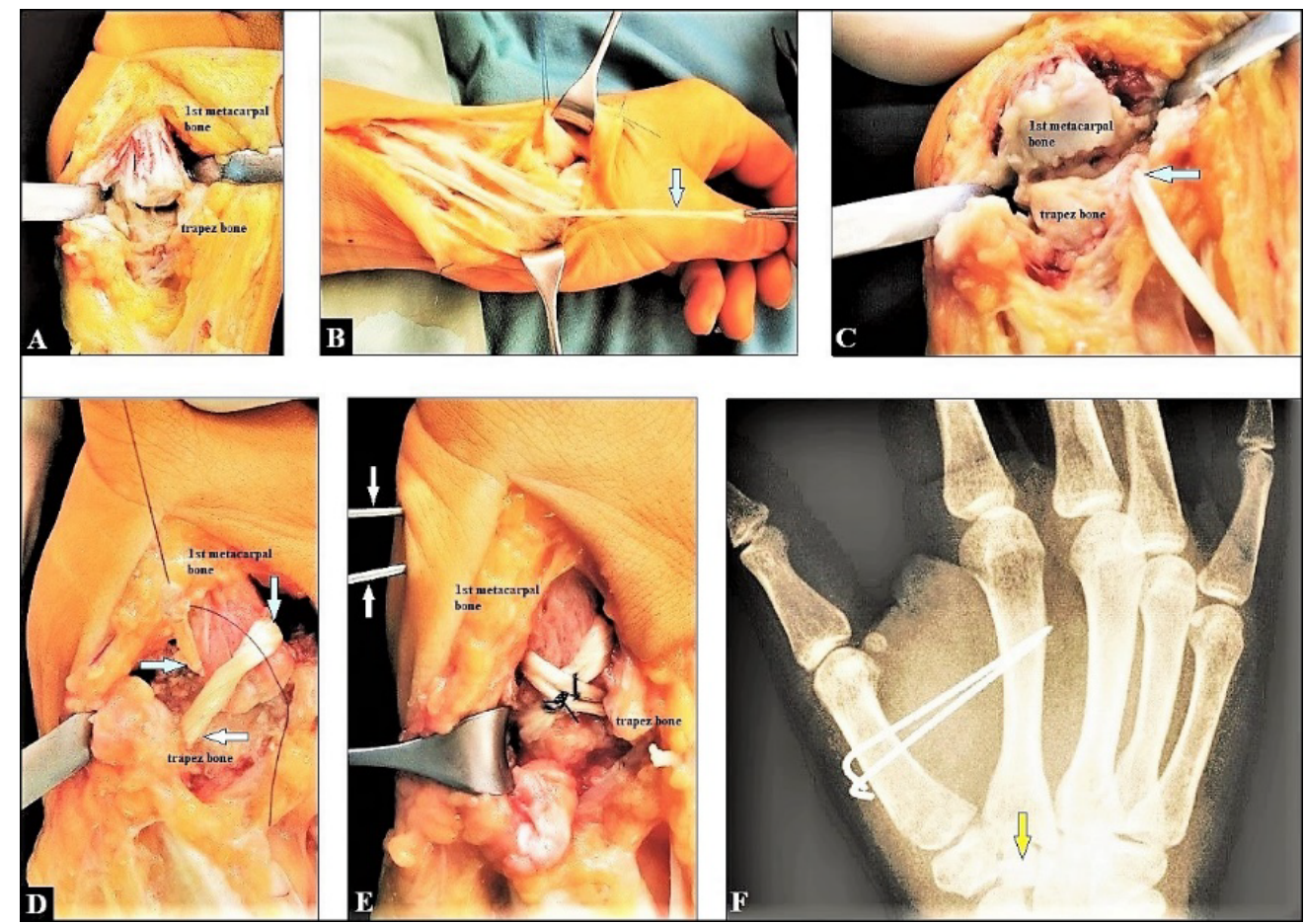

Figure 5 (A 32-year-old female presented with a right CMCJ I dislocation injury after a fall while alpine skiing, intraoperative clinical photographs and postoperative PA radiograph). (A) The dorsal capsule and ligaments were completely disrupted. (B) Dissection of a distally pedicled abductor pollis longus tendon slip. (C) Passing the tendon slip through a bony tunnel of the trapez bone. (D) Passing the tendon slip through a bony tunnel of the opposing metacarpal bone. (E) Suturing of the tendon slip with itself. (F) The CMCJ I was immobilized for six weeks postoperatively utilizing transmetacarpal K-wire transfixation 


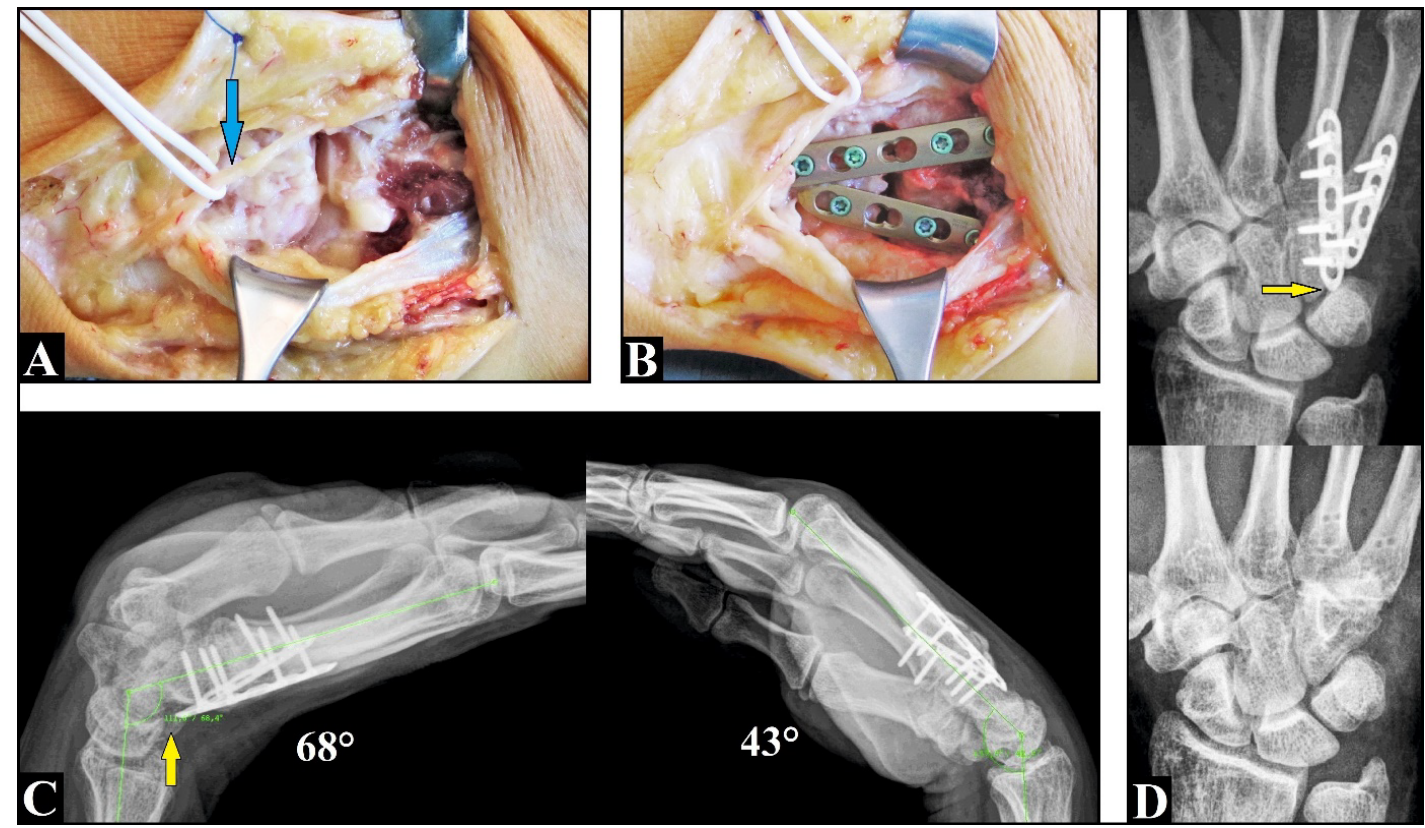

Figure 6 (26-year-old male, chronic painful instabilities of the right CMCJ IV and V after a fall from $2 \mathrm{~m}$ height one year previously, primarily diagnosed as joint sprain and treated conservatively by splinting). (A) Intraoperative clinical photograph showing the ligamentous instabilities at the CMCJ IV and V. The dorsal cutaneous branch of the ulnar nerve was carefully dissected and obtained (arrow). (B) Intraoperative clinical photograph showing the fusions of both CMCJs utilizing two 2,0 mm titanium locking plates. After resection of the corresponding articular surfaces the joint spaces were filled off with cancellous iliac crest bone grafts. (C) Lateral radiographs one year after surgery demonstrating an excellent functional outcome for the wrist, but noted that there was a painful impingement between the radial-sided titanium plate and the pisiforme bone at terminal range of active extension (arrow). (D) PA radiographs one year after surgery (before and after removal of both plates) showing complete bony fusions of both CMCJs. Note that the radial-sided titanium plate compromised the pisiforme bone (arrow)

problem due to its ulnar-sided complete overlapping by the hook of the hamate bone. Thus, a postoperative CT after a closed reduction procedure must be recommended by us in every instance. In the literature there are only a few case reports about persistent instability after closed reduction and it was stated that only an open reduction is able to guarantee anatomical reduction [31].

The therapeutic approach involves both closed and open reduction procedures with or without CMCJ transfixation using K-wires. For the recovery of polytraumatized patients it is absolutely necessary to achieve the earliest possible mobilization involving their independence in daily life for example to perform body hygiene that requires sufficient wrist motion [1]. The extension-flexion motion arc is realized with a relative portion of approximately $50 \%$ of both in radiocarpal and midcarpal joint, and for radial-ulnarduction the opposite shift of the proximal carpal row is needed [32]. Therefore, it is recommended that the K-wires should not cross the midcarpal joint, and additionally in order to avoid a breakage of the $\mathrm{K}$-wires if wrist motion is freed. The difference in the therapeutic approach to the CMCJ I dislocation injury is that here an open reduction combined with a ligamentous repair should be recommended in every instance in order to obtain a stable thumb's circumduction [Figures 5A-F] [33].

Delayed diagnosis and/or reduction usually result in undesirable outcome of pain, reduced grip strength, and degenrative arthritis that is comparable to those after MCPJ dislocation injuries [30,34,35]. However, despite sufficient management of CMCJ dislocation injuries $43 \%$ of patients reported residual pain and impaired function, and $13 \%$ of patients can not return to full work and sporting activities [36]. For persisting chronic and painful CMCJ instability or symptomatic arthritis CMCJ fusion will be inevitable [Figures 6A-D] [33,37].

\section{Conclusion}

Concerning our presented case there are five keystones: (1) it is unclear if there was a persistent or a recurrent (sub)dislocation within one day after the closed reduction procedure with our patient, (2) the CMCJ IV seems to be the main problem in radiographic assessment that is based on its partial overlapping by the hook of the hamate bone, (3) CT scans should be done in every instance after closed reduction with or without K-wire transfixation, or a primary injury of a CMCJ is suggested clinically and the radiographs do not allow an exact assessment, (4) transfixation of each CMCJ utilizing two K-wires without crossing the midcarpal joint allows an early active motion of both for the wrist and all finger joints which is an important factor for a required early mobilization and recovery of a polytraumatized patient, and (5) a CMCJ dislocation injury must be considered as a predicting factor for development of post-traumatic osteoarthritis.

\section{Declaration of conflicting interests}

The author declares no potential conflicts of interest with respect to the research, authorship, and/or publication of this article.

\section{Funding}

None.

\section{References}

1. Schmidt I, Markgraf E, Friedel R (1997) Die Handverletzung beim Polytrauma. OPJOURNAL 13: 146-150 (Thieme, Stuttgart-New York).

2. Mueller JJ (1986) Carpometacarpal dislocations: report of five cases and review of the literature. J Hand Surg Am 11: 184-188. [Crossref]

3. Fotiadis E, Svarnas T, Lyrtzis C, Papadopoulos A, Akritopoulos P, et al. (2010) Isolated thumb carpometacarpal joint dislocation: a case report and review of the literature. $J$ Orthop Surg Res 5: 16. [Crossref] 
Schmidt I (2021) Update to the difficulties in diagnostic and therapeutic management of the rare carpometacarpal joint II-V dislocation injuries: Case presentation and review of literature

4. Beylich T, Schmidt I (2021) Open Dislocation Injury of the Metacarpophalangeal Joints III-V: Case Report. Plast Reconstr Surg Glob Open 9: e3424.

5. Henderson JJ, Arafa MA (1987) Carpometacarpal dislocation. An easily missed diagnosis. J Bone Joint Surg Br 69: 212-214. [Crossref]

6. Jameel J, Zahid M, Abbas M, Khan AQ (2013) Volar dislocation of the second, third, and fourth carpometacarpal joints: a rare and easily missed diagnosis. $J$ Orthop Traumatol 14: 67-70. [Crossref]

7. Regel G, Lobenhoffer P, Lehmann U, Pape HC, Pohleman T, Tscherne H (1993) Results of treatment of polytraumatized patients. A comparative analysis of 3,406 cases between between 1972 and 1991. Unfallchirurg 96: 350-362

8. Ruchholtz S, Nast-Kolb D, Waydhas C, Schweiberer L (1996) The injury pattern in polytrauma. Value of information regarding accident process in clinical acute management. Unfallchirurg 99: 633-641.

9. Welkerling H, Wening JV, Langemdorff HU, Jungbluth KH (1991) Computer-assisted data analysis of injuries of the skeletal system in polytrauma patients. Zentralbl Chir 116: $1263-1272$

10. Reynolds BM, Balsano NA, Reynolds FX (1971) Falls from height: a surgical experience of 200 consecutive cases. Ann Surg 174: 304-308. [Crossref]

11. Schaller P, Geldmacher J (1994) Hand injury in polytrauma. A retrospective study of 782 cases. Handchir Mikrochir Plast Chir 26: 307-312. [Crossref]

12. Gurland M (1992) Carpometacarpal joint injuries of the fingers. Hand Clin 8: 733-744. [Crossref]

13. Sharma AK, John JT (2005) Unusual Case of Carpometacarpal Dislocation of All Four Fingers of Ulnar Side of Hand. Med J Armed Forces India 61: 188-189. [Crossref]

14. Yoshida R, Shah MA, Patterson RM, Buford Jr WL, Knighten J, Viegas SF (2003) Anatomy and pathomechanics of ring and small finger carpometacarpal joint injuries. $J$ Hand Surg Am 28: 1035-1043. [Crossref]

15. El-Shennawy M, Nakamura K, Patterson RM, Viegas SF (2001) Three-dimensional kinematic analysis of the second through fifth carpometacarpal joints. J Hand Surg Am 26: 1030-1035. [Crossref]

16. Pundkare GT, Patil AM (2015) Carpometacarpal Joint Fracture Dislocation of Second to Fifth Finger. Clin Orthop Surg 7: 430-435. [Crossref]

17. Metz VM, Wunderbaldinger P, Gilula LA (1996) Update on imaging techniques of the wrist and hand. Clin Plast Surg 23: 369-384. [Crossref]

18. Hartwig RH, Louis DS (1979) Multiple carpometacarpal dislocations: a review of four cases. J Bone Joint Surg Am 61: 906-908. [Crossref]

19. Hems TE, Simpson H (1992) Prevention of hand injuries in cycle accidents. J Trauma 32: 683-685.

20. Chardel P (2000) Dislocations and Fracture Dislocations of the Carpometacarpal Joints of the Fingers and Thumb. Emerg Surg Hand 6: 829.

21. Kural C, Başaran SH, Ercin E, Bayrak A, Bilgili MG, Baca E (2014) Fourth and fifth carpometacarpal fracture dislocations. Acta Orthop Traumatol Turc 48: 655-660. [Crossref]
22. Kumar R, Malhotra R (2001) Divergent fracture-dislocation of the second carpometacarpal joint and the three ulnar carpometacarpal joints. J Hand Surg Am 26 : 123-129.

23. Chikate A, Mthethwa J (2017) A Review of the Diagnosis and Management of Index through Fifth Carpometacarpal Dislocations. MOJ Orthop Rheumatol 9: 00534.

24. Jari S, Waseem M, Srinivasan MS (2000) Simultaneous Bennett's fracture and metacarpophalangeal dislocation of the same thumb in a soccer player. Br J Sports Med 34: 463-464. [Crossref]

25. Kocazeybek E, Demirel M,Arzu U,Ergin ON (2018) Simultaneous metacarpophalangea dislocation and carpometacarpal fracture-dislocation of the ring finger: a case report. $J$ Orthop Case Rep 8: 68-70. [Crossref]

26. Gaheer RS and Ferdinand RD (2011) Fracture dislocation of carpometacacarpal joints a missed injury. Orthopedics 34: 399 .

27. Brinkman JN, Hartholt KA, de Vries MR (2016) Multiple carpometacarpal dislocations and an associated fracture of the hamate: an uncommon injury. BMJ Case Rep 2016: bcr2015213106.

28. Feder OI, Letzelter JP, Haquebord JH (2021) Dorsal Dislocation oft he Trapezoid with Metacarpal Instability. $J$ Wrist Surg DOI: 10.1055/s-0040-1715801 (eFirst).

29. Fitschen-Oestern S, Lippross S, Lefering R et al. (2020) Missed hand and forearm injuries in multiple trauma patients: An analysis from the TraumaRegister DGU®. Injury 51: 1608-1617.

30. Woon CYL, Chong KC, Low CO (2006) Carpometacarpal joint dislocations of the index to small finger: Three cases and a review of literature. Injury Extra 37: 466-472.

31. Kimura H, Toga A, Suzuki T, Iwamato T (2021) Open Reduction for Dorsal Dislocation of Second to Fifth Carpometacarpal Joints: A Case Report. J Wrist Surg DOI: 10.1005/ s-0040-1715802 (eFirst)

32. Schmidt I (2019) Functional Outcomes After Salvage Procedures for Wrist Trauma and Arthritis (Four-Corner Fusion, Proximal Row Carpectomy, Total Wrist Arthroplasty, Total Wrist Fusion, Wrist Denervation): A Review of Literature. Open Orthop J 13: 217-231.

33. Schmidt I (2018) The various patterns of dislocation injuries at the carpometacarpal joints: A case series and brief review of literature with regards to the main topics. Trauma Emerg Care 3.

34. Imbriglia JA (1979) Chronic dorsal carpometacarpal dislocation of the index, middle, ring, and little fingers: a case report. J Hand Surg Am 4: 343-345. [Crossref]

35. Dinh P, Franklin A, Hutchinson B, Schnall SB, Fassola I (2009) Metacarpophalangeal joint dislocation. J Am Acad Orthop Surg 17: 318-324. [Crossref]

36. Lawlis 3rd JF, Gunther SF (1991) Carpometarpal dislocations. Long-term follow-up. $J$ Bone Joint Surg Am 73: 52-59. [Crossref]

37. Büren C, Lögters T, Gehrmann S, Windolf J (2016) Carpometacarpal fracture dislocations. OUP 2: 088-093.

Copyright: (C2021 Schmidt I. This is an open-access article distributed under the terms of the Creative Commons Attribution License, which permits unrestricted use, distribution, and reproduction in any medium, provided the original author and source are credited. 